\title{
PERFIL CLÍNICO E SOCIODEMOGRÁFICO DOS PACIENTES HEMODIALÍTICOS DE UMA UNIDADE DE HEMODIÁLISE DE TAUBATÉ-SP
}

\author{
Fernanda Aparecida Silva ${ }^{1}$ \\ Sarah de Lima Resende ${ }^{2}$ \\ Samantha de Lima Resende ${ }^{3}$ \\ Daiane Cassandra de Oliveira ${ }^{4}$ \\ Jaqueline Magalhães Gonçalves ${ }^{5}$ \\ Poliana Turino da Silva Monteiro ${ }^{6}$ \\ Teresa Celia de Mattos Moraes dos Santos ${ }^{7}$ \\ Eliana Fatima de Almeida Nascimento ${ }^{8}$ \\ Ana Lucia De Faria ${ }^{9}$
}

\begin{abstract}
Resumo - A Insuficiência Renal Crônica é a perda progressiva e irreversível da função renal. Objetivo: Avaliar o perfil clínico e sociodemográfico dos pacientes hemodialíticos de uma Unidade de Hemodiálise de Taubaté-SP. Método: Pesquisa prospectiva, descritiva e quantitativa. Resultados: Prevaleceu o sexo feminino em 55,46\%, a faixa etária entre 80 e 90 anos de idade em 21,85\%, casados em 54,62\%, etnia branca em $44,54 \%$, ensino fundamental em $47,90 \%$, católicos em $72,27 \%$, aposentados em $42,86 \%$, após a hemodiálise destacou a hipotensão em 56,81\%, tempo de hemodiálise 1 a 2 anos em 40,34\%, três sessões por semana em 100\%. Conclusão: Conclui-se que o perfil dos pacientes hemodialíticos foi: sexo feminino, faixa idade entre 80 e 90 anos de idade, casadas, de etnia branca, ensino fundamental, católicos, aposentados, hipotensão após a hemodiálise, tempo de 1 a 2 anos de hemodiálise, três sessões de hemodiálise por semana.
\end{abstract}

Palavras-chave: Enfermagem; Reabilitação; Mortalidade.

\footnotetext{
1 Curso de Enfermagem/Universidade de Taubaté, Brasil. E-mail: fernandynhaaparecida@gmail.com.

2 Curso de Enfermagem/Universidade de Taubaté, Brasil. E-mail: sarinha_delimarezende@hotmail.com.

${ }^{3}$ Curso de Enfermagem/Universidade de Taubaté, Brasil. E-mail: sah_rezende@hotmail.com.

4 Curso de Enfermagem/Universidade de Taubaté, Brasil. E-mail: daianecassandra@yahoo.com.

${ }^{5}$ Curso de Enfermagem/Universidade de Taubaté, Brasil. E-mail: jake_rafa2014@hotmail.com.

${ }^{6}$ Curso de Enfermagem/Universidade de Taubaté, Brasil. E-mail: polianatsm94@hotmail.com.

7 Curso de Enfermagem/Universidade de Taubaté, Brasil. E-mail: teresacelia@terra.com.br.

8 Curso de Enfermagem/Universidade de Taubaté, Brasil. E-mail: efanascimento@yahoo.com.br.

${ }^{9}$ Curso de Enfermagem/Universidade de Taubaté, Brasil. E-mail: anadinda2002@yahoo.com.br.
} 